\title{
IMAGINARIO Y SOCIEDAD Un acercamiento a la sociología de lo imaginario en la tradición francesa
}

\author{
IMAGINARY AND SOCIETY \\ An Approximation to the Sociology of the Imaginary Thing \\ in the French Tradition
}

ÁNGEL ENRIQUE CARRETERO PASÍN

Grupo Compostela de Estudios sobre Imaginarios Sociales. Universidad de Santiago de Compostela

\author{
PALABRAS CLAVE ADICIONALES ADDITIONAL KEYWORDS \\ Mito, Sagrado, Cotidianeidad, Poder, Utopía. $\quad$ Myth, Asylum, Routine Character, Power, Utopia.
}

\begin{abstract}
RESUMEN. Este trabajo es una aproximación a los elementos fundamentales sobre los que gira la corriente sociológica francesa conocida como la sociología de lo imaginario. En primer lugar, fija su atención sobre el análisis de aquellas tradiciones teóricas que han contribuido a gestar esta corriente, en especial el pensamiento antropológico-sociológico de Gilbert Dürand y las aportaciones durkheimianas de la Escuela sociológica francesa. A continuación, plantea la relevancia sociológica de la noción de imaginario como un novedoso acercamiento a la comprensión de la realidad social, desglosando sintéticamente las directrices esenciales sobre las que esta corriente gravita e incidiendo en cinco aspectos: la persistencia del mito y lo sagrado, la implicación de lo imaginario en la cotidianeidad, la interpretación de la vida cotidiana, la ligazón entre lo imaginario y lo político y el fundamento imaginario de la utopía.
\end{abstract}

ABSTRACT. This work is an approach to the fundamental elements on which it turns the specially French sociological current known as sociology of the imaginary thing. In the first place, it fixes his attention on the analysis of those theoretical traditions that have contributed to develop this current, the anthropological-sociological thought of Gilbert Dürand and the durkheimian contributions of the French sociological School. Next, it raises the sociological relevance of the notion of imaginary like a new approach to the understanding of the social reality, synthetically detachhing the essential directives on which this current weighs affecting five aspects: the persistence of the myth and the asylum, the implication of the imaginary thing in the routine character, the interpretation of the daily life, the attachment between imaginary and the politician and the imaginary foundation of the utopia.

E-mail: quiquecarretero@terra.es

Revista Internacional de Sociología (RIS)

Tercera Época, № 41, Mayo-Agosto, 2005, pp. 137-161. 
R I S

REVISTA INTERNACIONAL DE SOCIOLOGIA

$\mathrm{N}^{\circ} 41$, MAYO-AGOSTO, 2005

ÁNGEL ENRIQUE CARRETERO PASÍN

\section{INTRODUCCIÓN}

El término "imaginario" ha sido utilizado con frecuencia en el campo de las ciencias humanas y sociales, aunque a menudo de una manera un tanto vaga e imprecisa. Así, la recurrencia a lo imaginario apelaría en muchos casos al ámbito del sueño, del deseo, de la fantasía, a un orden de la experiencia individual y colectiva que extralimitaría el de la realidad, la racionalidad y la lógica. Es bien notorio que en la vertiente específica de un paradigma racionalista se le ha atribuido a la acepción de "imaginario" la connotación de quimera o ilusión, de la cual sería necesario desembarazarse para alcanzar un recto y fidedigno juicio en consonancia con una correcta aplicación de la razón. En un diferente contexto teórico, el del psicoanálisis lacaniano, el vocablo "imaginario" indicaría una fantasiosa sublimación derivada y estimulada desde una carencia o falta previa de carácter psicológico. La ambigüedad, la indefinición, pues, parecen ser los rasgos que acompañan reiteradamente el empleo de este término en disciplinas como la sociología, la antropología, la filosofía o la psicología.

Conviene, pues, circunscribir de antemano nuestra particular utilización de la noción de imaginario a una línea de investigación concreta, aquella auspiciada en Francia a raíz de la formulación por parte de Gilbert Dürand de una socio-antropología de lo imaginario. En 1960, Dürand propondrá en su emblemática obra Las estructuras antropológicas de lo imaginario una alternativa teórica al estructuralismo de Claude Lévi-Strauss, dominante en ese momento en el panorama de las ciencias humanas francesas, catalogada como estructuralismo figurativo y cuyo empeño radicará en radiografiar la arquitectura trascendental que anida en lo imaginario. En ese esfuerzo, Dürand descubre una función eufemizadora en la imaginación de la que emana un dinamismo creativo, a través del cual el hombre busca compensar las carencias y desajustes provocados por una civilización caracterizada por una hipertrofia de lo racional desencadenante de una reificación cultural. Dicho dinamismo creativo, finalmente, se traducirá en la configuración de un fecundo universo simbólico-mitológico. Una vez cristalizado, este universo imaginario estructura y conforma nuestra peculiar asunción de lo real, confiriéndole una significación global a nuestra particular experiencia social. De modo que, desde la original aportación teórica de Dürand, es preciso concebir lo imaginario como un ámbito propiamente inmaterial, pero, no obstante, constituyente esencial de toda realidad social. Como luego desglosaremos, la propuesta durandiana propiciará la emergencia de una novedosa concepción de la ciencia social, que pondrá énfasis en una hermenéutica de los aspectos imaginarios implícitos en lo social y que, en razón de lo anterior, anhelará convertirse en alternativa metodológica y epistemológica al paradigma positivista reinante en las ciencias sociales. 


\section{LOS PRECURSORES DE UNA SOCIOLOGÍA DE LO IMAGINARIO}

Habrá que esperar a los albores del pasado siglo para que el dominio, hasta entonces difuso, de lo imaginario se comience a perfilar como un campo específico de estudio con consistencia propia. Para ello, será necesario previamente doblegar la resistencia intelectual que ofrecía una mentalidad racionalista y positivista fuertemente anclada en las directrices que marcaban el rumbo de las ciencias humanas. A partir de la obra de Henri Bergson (1996:125-263), la ficción, la fabulación, en lugar de ser subestimadas como ilusorios e incongruentes productos derivados de la mente humana, se erigen en constituyentes esenciales para la pervivencia de la vida individual y colectiva, reconociéndosele, de este modo, una lógica vivencial a aquello que fuera catalogado simplificadoramente como ilógico o irracional ${ }^{1}$. En este proceso de emergencia de un saber de lo imaginario será también especialmente descollante la figura de Gaston Bachelard, quien buscará desentrañar la fecundidad poética subyacente en ciertos elementos de la naturaleza, poniendo de relieve la facultad de la que dispone la imaginación, en cuanto resabio de un mundo onírico infantil doblegado a los imperativos de la realidad, para reintroducir el ensueño en aquello más cercano. La imaginación, para Bachelard, es, pues, una fuente de creación que ensancha el horizonte de posibilidades de lo dado, desvelándonos una latente significación poética que irriga y vivifica lo real. Desvinculándose tanto de la rígida esquematización y racionalización freudiana de la naturaleza de lo onírico como de la fenomenología husserliana por su desapego a lo concreto, Bachelard (1997) plantea una verdadera ontología con una motivación de asistematicidad y en la que la imaginación, como alternativa al rigor conceptualista albergado en la tradición racionalista, se convierte en una vía privilegiada de conocimiento, por otra parte ya vislumbrada con anterioridad en el romanticismo. En consonancia con el distanciamiento con respecto al paradigma racionalista, prevaleciente a comienzos del siglo pasado, de Bergson y Bachelard, desde otro ángulo la obra de Ernst Cassirer insistirá en la recuperación de las formas simbólicas como la localización natural en la que se expresa el ámbito de la cultura humana. Frente a la hegemonía del modelo explicativo-causal que ansiaba reducir el desciframiento del comportamiento individual y colectivo a leyes de carácter general y universal, Cassirer (1972) reintroduce una concepción del hombre y la experiencia social en la que se pone énfasis en aquellas elaboraciones culturales cuyo fundamento es la naturaleza de lo simbólico, siempre irreductible a los cánones establecidos en el cientifismo.

\footnotetext{
${ }^{1}$ La idea central que propone Bergson en esta obra es la tendencia natural del hombre a fabricar espíritus y dioses a través de su inherente facultad fabuladora. Aquello que había sido, entonces, devaluado por la tradición intelectualista y teoricista, dominante en Occidente a raíz del racionalismo cartesiano, recupera una relevante significación antropológica previamente despreciada.
} 
RIS

REVISTA INTERNACIONAL DE SOCTOLOGIA

№ 41, MAY0-AGOST0, 2005

ÁNGEL ENRIQUE CARRETERO PASÍN

En la consolidación de un saber de lo imaginario va a tener un papel predominante la obra de Gilbert Dürand con su vinculación a la Escuela de Eranos. En su tesis doctoral, Las estructuras antropológicas de lo imaginario, publicada por vez primera en 1960 y en la actualidad en la decimoprimera reedición en francés, Dürand acomete una empresa teórica interdisciplinaria de una envergadura excepcional, encaminada a construir una socio-antropología de lo imaginario en donde la metapsicología de Carl Gustav Jung y la fenomenología religiosa de Mircea Eliade resuenan de una manera especial. Influenciado primordialmente por estos dos autores y por su maestro Bachelard, Dürand sostiene la existencia de una persistencia latente de lo arcaico que se expresaría, en el interior de una secularizada modernidad, por medio de unas recurrentes imágenes arquetipicas. Lo arquetípico, entonces, nos remitiría a un ámbito matricial transhistórico, a unas estructuras profundas, perennes y fundacionales que, a modo de constante cultural, subyacen tras cada concreción cultural y se reactualizan bajo modulaciones diferenciadas ${ }^{2}$. Y, en este sentido, distingue un doble régimen arquetípico: por una parte, un régimen diurno que conduce a un espíritu de dominio, racionalidad, cientificidad, que no se deja seducir por la embriaguez y que lleva asociado un componente de ascesis y, por otra parte, un régimen nocturno con una figuración femenina y caracterizada por un espíritu mistico en el que predomina una voluntad afectiva de unión e intimidad.

En La imaginación simbólica (1971), Dürand entiende que el racionalismo y el positivismo que impregnan el decurso de la historia del pensamiento occidental, incluido el estructuralismo de Lévi-Strauss, se caracterizan por un espíritu iconoclasta en el que se eclipsa la inherente fecundidad de lo simbólico para evocar lo irrepresentable y transcender la representación sensible para remitirnos a un sentido invisible. De manera que el primado de una iconoclasta objetividad científica, de la ciencia como nuevo mito, privaría al hombre de la natural predisposición que alberga el símbolo para mediar con lo transcendente. De este modo, el orden de lo imaginario haría alusión a las elaboraciones culturales que, solidificadas bajo la forma de mito, nacen de un desafio de la condición humana frente a los efectos de una temporalidad que desgasta, frente a la sombra de la muerte como su designio natural. Con lo cual, lo imaginario vivifica unas petrificadas estructuras culturales resultantes de la consagración de una excluyente racionalidad tecno-científica y modela, una vez cristalizado como matriz de significación central, la totalidad de la experiencia social. Frente a una actitud desmitificadora en la que el mito es objeto de sospecha, al atribuírsele una suerte de falsificación de lo real, de sublimación fantasiosa que oculta una subyacente lógica histórica o libidinal, presente en el

\footnotetext{
${ }^{2}$ La noción de arquetipo puede encontrase expuesta fundamentalmente en Jung (1991). Un acercamiento a la comprensión de la naturaleza del arquetipo, eclipsada por el historicismo y el progresismo reinantes en la atmósfera intelectual de la segunda mitad del siglo XIX, puede verse en Eliade (1999) y (2000).
} 
marxismo, en el psicoanálisis freudiano o en la semiología de Roland Barthes, Dürand apuesta por una comprensión de la vida social en la que se incidirá en la facultad remitificadora propia de lo imaginario. Lo imaginario, así, sería, un anhelo esperanzador capaz de transmutar la conversión del hombre en reificada objetividad desposeída de un sentido que sacie su indigencia existencial. El mito, desde esta perspectiva, se hallaría inevitablemente presente y estaría impregnando los diferentes contextos en los que se desenvuelve la vida colectiva. Aquí, bajo un latente trasfondo trágico, es donde encuentra su principal anclaje la función eufemizadora de lo imaginario, en cuanto instauradora de un dinamismo creativo que se rebela ante el reconocimiento de la fugacidad de la existencia, a la vez que busca una compensación, a través de una remagización transfiguradora de lo real, a un mundo desencantado (Dürand,1982:404-409; 1971:126-127)3. La fuerza de la imaginación, de la que se nutre lo imaginario, piensa Dürand, recogiendo las orientaciones teóricas de Henry Corbin en su análisis del sufismo islámico, reposa sobre una condición gnóstica del espíritu humano, que apelaría a una naturaleza propiamente transcendental de la creatividad de la que se segrega la irrealidad, un mundus imaginalis. Así pues, existiría, a juicio de Dürand, una verdadera ontología de la imaginación, más allá de una mera identificación de ésta a una facultad psicológica, en cuanto mediadora entre lo visible y lo invisible, entre lo sensible y el misterio ${ }^{4}$.

Desde una diferente vertiente teórica, en este caso con un mayor acento sociológico, la génesis de una sociología de lo imaginario se nutre de la línea de investigación en torno a una sociología de lo sagrado, que había sido auspiciada especialmente por la obra tardía de Emile Durkheim y por la colaboración entre éste y Marcel Mauss, y prolongada en la década de los años treinta del pasado siglo en Francia con el programa fundacional del Collège de Sociologie, integrado por Roger Caillois, Michel Leiris, Alexandre Kojève y Georges Bataille, aunque en este contexto tampoco debiera pasar inadvertida la figura de Roger Bastide.

En la explicación durkheimiana de la naturaleza del fenómeno religioso, que se remonta a las primeras manifestaciones totémicas en religiones primitivas, se

\footnotetext{
${ }^{3}$ Una vez fundamentado, en los años sesenta, un marco teórico destinado a profundizar en la naturaleza de lo imaginario, Dürand prolongará posteriormente su prolifica línea de investigación en torno a campos tan diferentes como la literatura, la mitología o la fundamentación de las ciencias humanas. A este respecto, nos remitimos a Dürand (1980); (1984); (1993); (1999); (2000).

${ }^{4}$ El estudio de este carácter transcendental de la imaginación puede verse en Corbin (1993:209284). Según Corbin, en la teosofia mística de Ibn 'Arabî la creación es esencialmente una teofanía (tajalli), un acto del poder imaginativo divino, no siendo la imaginación activa del ser humano más que el órgano de expresión de la imaginación teofánica absoluta. Por otra parte, piensa Corbin, esta potencia mágica creadora sobre la que descansa la imaginación, tan ensalzada en el romanticismo, tiene su origen en el anhelo, consustancial al ser humano, "de superar la realidad en su estado de hecho, así como la soledad de mi yo entregado a sí mismo (el nada-más-que yo, Nur-Ich-Sein, cuya obsesión puede hacer bordear la locura) en este mundo que nos viene impuesto" (Corbin, 1993:210).
} 
le concede a la religión la facultad que garantiza la integración simbólica de la sociedad y, de este modo, configura un espacio de cohesión e identidad social. Durkheim (1982:387-414) había insistido en la necesidad de un ideal social, de una autorrepresentación colectiva, históricamente encarnada en el dominio de lo religioso, que posibilite una conciencia común sobre la que descansa la propia supervivencia de la sociedad. De modo que, más allá de una concepción dualista en la que se escinde lo material y lo ideal, la religión es un elemento consustancial a la misma vida social, es una transcendencia inmanente que está implicada y conforma lo socials.

La perspectiva en torno a la religión de Durkheim abocaba a una innovadora propuesta orientada a extender el espacio de lo sagrado más allá del estrecho marco de una específica circunscripción eclesiástica, o de los márgenes establecidos por una dogmática doctrinal concreta, facilitando la posibilidad de una elucidación de lo sagrado que operaba en el seno mismo de una modernidad aparentemente secularizada. Dado que el sociologismo durkheimiano implicaba un claro distanciamiento con respecto a una formulación sustantiva del hecho religioso de raigambre fenomenológica al modo de Rudolf Otto o Mircea Eliade, estimulaba una novedosa aproximación a la comprensión de distintas manifestaciones profanas en las que se estaría expresando lo sagrado. De ahí que, con posterioridad, Roger Caillois (1989:95-99), en un texto destinado a establecer los lineamientos generales sobre los que debiera sustentarse el programa fundacional del Collège de Sociologie, proponga el nombre de sociología sagrada al estudio de la experiencia social en todas aquellas exteriorizaciones en donde se revelaría la presencia activa de lo sagrado, tales como las iglesias, los ejércitos, las fraternidades y las sociedades secretas. En síntesis, la inquietud sociológica en torno a la que se congregarán Caillois, Leiris o Bataille se encaminará hacia el desvelamiento de la radicalidad de los elementos antropológicos inscritos en la vida colectiva que habían sido soterrados bajo una unidimensional concepción de lo social en la que predominaba preferentemente lo racional, tratando de poner de relieve aquello que, excluido por el modelo de racionalidad afianzada en Occidente, pervive en el núcleo de la existencia social y confiriendo al mito, al juego, a lo sagrado, un destacado poder para despertar un deseo de alteridad y canalizar una latente energía colectiva. Lo pasional, lo instintivo, lo dionisiaco recobran, entonces, una significación cultural desterrada por una modernidad que gravita sobre una acentuada racionalización capilarizada por la totalidad del entramado social. Así, Bataille (1987 y 1993) opondrá a la parte homogénea de lo social —aquella reducible a un cálculo racional al servicio de la utilidad productiva - la heterogénea

\footnotetext{
${ }^{5}$ Véase, también, la anticipación de esta idea en Durkheim (2000: 27-86), así como el excelente estudio de lo sagrado en el pensamiento durkheimiano en Prades (1998).
} 
- en donde se incluye el maná y el tabú, como materializaciones de lo sagrado, el gasto improductivo, la violencia, la desmesura, la locura y, en general, todos aquellos ámbitos difícilmente constreñibles a la homogeneidad. Caillois (1938; 1958 y 1996) enfatizará en cómo el espacio de lo festivo representa un ámbito de transgresión social en donde encuentra su anclaje lo sagrado, en cómo el mito canaliza la procura de una satisfacción instintiva que la realidad bloquea y en cómo lo fantástico, lo irreal, implica una amenazadora fractura, una irrupción insólita, que quiebra la estabilidad del curso de los acontecimientos cotidianos. En una línea similar, los estudios americanistas de Roger Bastide, en especial los dedicados a la cultura brasileña, introducen el saber socio-antropológico en el difuso terreno de lo onírico, mostrando cómo en las llamadas sociedades primitivas el mundo del sueño, que nos vincularía al mito, está perfectamente imbricado en sus prácticas cotidianas. Es posteriormente, como resultado del proceso de secularización de la cultura y de la creciente importancia asignada a la producción en las sociedades occidentales, cuando el sueño se ve desplazado hacia una ubicación fronteriza en el terreno de lo imaginario. Así, mientras en las sociedades primitivas el mundo imaginario está totalmente imbricado consustancialmente en ellas, en una solución de continuidad con el mundo real, el despliegue de la modernidad es el factor que fractura este cordón umbilical que liga realidad y sueño. De ahí que, según Bastide (1972:48-62), lo imaginario se haya erigido en ese privilegiado espacio residual en donde aún pueda expresarse la fuerza vivificadora del sueño que coloniza la realidad. Al mismo tiempo, Bastide (1970:263-303) descubre una importante ligazón natural existente entre el mito, como condensación de lo imaginario, y la utopía que dinamiza históricamente a los movimientos mesiánicos, problematizando, de este modo, la estrecha identificación del mito a un "habla despolitizada" al modo como era considerado por Barthes ${ }^{6}$.

En este sucinto recorrido por los antecedentes de una sociología de lo imaginario hemos intentado focalizar nuestra atención sobre aquellas figuras más relevantes del panorama filosófico, antropológico y sociológico, o sobre aquellas líneas de investigación concretas que, explorando y reconociendo la relevancia cultural de lo imaginario, han fijado, como luego desglosaremos, los pilares de una novedosa corriente sociológica orientada a una comprensión de la realidad social en la que se otorga una principal significación a lo imaginario. De ahí que hayamos prescindido intencionadamente de otras destacadas formulaciones de lo imaginario que, o bien se desmarcarían, o bien no entroncarían con las directrices fundamentales que conforman la tradición sociológica objeto de nuestro trabajo?

\footnotetext{
${ }^{6}$ En una línea análoga, véase Laplantine (1977). De Barthes véase (1999:232-257).

${ }^{7}$ Merecen ser señaladas tanto las aportaciones de Sartre (1964) como las de Castoriadis (1983 y 1989). En el primer caso, porque, pese a su reconocimiento de lo imaginario, no alcanzaría a dotar a éste de la radicalidad que merecería y, en el segundo, por pertenecer a una tradición de pensamiento (la de una reformulación del marco teórico del marxismo) distanciada de aquella que ocupa nuestra
} 


\section{LA SOCIOLOGÍA DE LO IMAGINARIO: UNA NUEVA PERSPECTIVA PARA LA COMPRENSIÓN DE LA REALIDAD SOCIAL}

La tradición sociológica francesa que enfatiza la relevancia de lo imaginario en la vida social surge en la década de los setenta del pasado siglo. Intenta aplicar la noción antropológico-filosófica de lo imaginario, propuesta por Dürand, al estudio de una pluralidad de fenómenos sociales contemporáneos, y se congrega, fundamentalmente, en torno a lo que se conoce como Escuela de Grenoble. Siguiendo la estela de Dürand, el denominador común en un conjunto de sociólogos, entre los que cabe incluir a Michel Maffesoli, Pierre Sansot, Patrick Tacussel, Jean Pierre Sironneau o Alain Pessin, y junto a los cuales se podría también mencionar las figuras de Georges Balandier, Raymond Ledrut o Edgar Morin, es el esfuerzo por construir un saber sociológico que, como contrapartida a la reinante epistemología positivista, apunte a la revalorización y desciframiento del componente imaginario que se inscribe en la vida social y la gobierna. Su intención cojunta, es la de reintroducir la imaginación sociológica en una ciencia en la que, a su juicio, se ha disuelto paulatinamente la originaria preocupación humanista, ineludiblemente presente en su proyecto fundacional, y se ha entronizado un excluyente modelo positivista como hegemónico. En consecuencia, la sociología francesa de lo imaginario no centrará tanto su interés en el análisis específico de determinadas estructuras económico-sociales, en el aspecto infraestructural de la vida social, cómo en la interpretación de las representaciones sociales, en una hermenéutica del componente mítico-simbólico, propiamente ideacional, que está implicado e irriga de significación a diferentes contextos puntuales de la vida cotidiana. Con las evidentes dificultades que entraña la radiografía general de una tradición que acoge una multiplicidad de sociólogos con unos rasgos diferenciales en cada caso, vamos a distinguir cinco aspectos esenciales sobre los cuales se vertebra un sentimiento de afinidad, una sensibilidad común, de la que cristaliza tanto un peculiar modo de entendimiento de la labor sociológica como de desciframiento de la realidad social.

\section{La persistencia del mito y de lo sagrado en la sociedad actual}

La sociología de lo imaginario se apoya sobre el presupuesto según el cual los ámbitos del mito y de lo sagrado, aparentemente superados en el proceso de secularización desencadenado en Occidente a raíz de la modernidad, siguen conservando un papel nuclear en la vida social. Entiende, en líneas generales, que el discurso ilustrado, adoptando una estrecha actitud racionalista e intelectualista, habría

investigación. Algo similar a lo que sucede con Castoriadis ocurre con la obra de Lacan, inmersa en una reformulación del bagaje psicoanalítico que se separa notablemente de la concepción de lo imaginario que recorre este trabajo. 
propugnado una simplificadora identificación del mito y de la religión como unas ilusorias representaciones del mundo que debieran ser enjuiciadas y finalmente denostadas desde el tribunal de la razón. En efecto, el proyecto desacralizador, consolidado en Occidente a partir de los siglos XVII y XVIII, buscaría desproveer a la religión de las preponderantes funciones que le fueran históricamente asignadas, a saber, ser fuente tanto de legitimación de la realidad socialmente instituida como de integración social, relegándola a la esfera exclusiva de la privacidad. Al mismo tiempo, el despliegue de la ciencia moderna contribuiría, en sintonía con lo anterior, al afianzamiento de una versión de la naturaleza reductible a un unilateral lenguaje físico-matemático y, en consecuencia, desprovista de otro tipo de cualidades. Pese a que no pueda hablarse de una influencia directa sobre ellos del desencantado análisis de la modernidad llevado a cabo por la primera generación de la Escuela de Frankfurt, los autores que integran esta corriente sociológica hacen suyo plenamente el lúcido diagnóstico cultural de Theodor Adorno y Max Horkheimer (1994: 59-95), para quienes la modernidad significó una conversión de la razón unidimensional en ella gestada en una forma de mitología a la que debieran plegarse los diferentes órdenes de la existencia social. De esta manera, el mito y la religión, representaciones del mundo resultantes del despliegue y de la condensación de lo imaginario, habrían sido finalmente desterrados de su papel nuclear en la vida social.

Un objetivo central en la sociología de lo imaginario, sin embargo, será mostrar que, a pesar de los pesimistas augurios de la modernidad, lo religioso y lo mítico, lejos de desaparecer del campo social, se transmutan en un novedoso rostro profano, se metamorfosean bajo nuevas materializaciones históricas entre las que cabe destacar las ideologías políticas o el culto litúrgico patriótico. A este respecto, la obra de Sironneau (1982:170-219) es profundamente esclarecedora de las mutaciones que han afectado a los órdenes de la religión y del mito a raíz de una modernidad en la que ambos parecían abocados a desaparecer de su espectro cultural. En líneas generales, esta tradición sociológica va a asumir, pues, un desplazamiento de lo sagrado de su antigua ubicación transcendente y su concreción en un abanico de hierofanías de carácter profano, desvelando, de este modo, una sutura abierta en el proceso secularizador desencadenado históricamente en Occidente. La gran revelación que nos muestra la modernidad, insistirá Ledrut (1984:155-173), es que, en cualquier tiempo y lugar, todo puede devenir en hierofanía, efímera o durable, inscrita en la vida colectiva, descubriendo una nueva verdad del mito en su forma presente ${ }^{8}$.

${ }^{8}$ Véase, también, la misma idea en Balandier (1994a:24-27). 


\section{RIS}

Así, lo arcaico, lo transhistórico, defenestrado por el espíritu progresista que inunda la mentalidad occidental a partir del siglo XVIII y reprimido por la hipertrófica racionalización de la experiencia social moderna, recobraría una especial relevancia sociológica, mostrándonos un trasfondo arquetípico que, a modo de constante cultural, perviviría y se reactualizaría en las sociedades actuales. La modernidad, al quebrar la tajante línea divisoria establecida en las sociedades tradicionales entre lo sagrado y lo profano, propiciará que la religiosidad se fije a figuras profanas, encarnándose en una multiplicidad de micromitologias que anidan, como bien han analizado Morin (1964) y Dorfles (1973), en diferentes localizaciones de la sociedad contemporánea ${ }^{9}$. Al mismo tiempo, ligado a lo anterior, la descomposición del universo simbólico religioso tradicional, que ofrecía una sólida oferta de sentido, provocará una liberación de lo sagrado que escaparía al control de las organizaciones que dispusieron históricamente del monopolio de su gestión, entrañará, como ha destacado Georges Balandier (1988:228-233; 1994a:143-179), que lo "sagrado moderno" entre a formar parte de las ritualizaciones de la vida cotidiana y aporte su fuerza a movimientos contestatarios; siempre como un anhelo de restitución de un sentido dañado por una desencantada secularización del mundo moderno, dando lugar al advenimiento de un neopoliteismo. $\mathrm{El}$ análisis de las nuevas mitologías y expresiones de religiosidad, presentes en la vida cotidiana, va a ocupar un lugar central, entonces, en la sociología de lo imaginario, aunque desmarcándose de la rigidez del marco teórico semiológico que había dominado el campo de las ciencias humanas y sociales durante los años sesenta. En consecuencia, el interés global que guiará a la sociología de lo imaginario será la aplicación de una hermenéutica que desentrañe la significación socio-cultural de una multiplicidad de mitos encarnados en figuras proxémicas y de unas manifestaciones de religiosidad profana que se encuentran firmemente ancladas en la cotidianeidad.

En este contexto, va a cobrar un especial relieve la noción de neotribalismo propuesta por Maffesoli (1990:133-182;1992:204-275;1993:200-220), a final de la década de los ochenta y comienzos de los noventa, como paradigma interpretativo de la lógica que rige las sociedades en las que la modernidad languidece.

\footnotetext{
${ }^{9}$ Morin equipara la relación que en la actualidad mantiene la gente con las estrellas cinematográficas a la que en otro tiempo mantenían con los grandes dioses de los panteones antiguos, en un esfuerzo por colmar, en última instancia, el ansia de inmortalidad que anida en el ser humano. De ahí que, sentencie Morin, "nadie es verdaderamente ateo si frecuenta las salas oscuras"(Morin,1964:83). Del mismo modo, Dorfles distingue, con acierto, entre lo mitagógico-mitos degradados a la condición de superstición-y lo mitopoyético - restitución de un valor simbólico a entidades que lo han perdido, valiéndose de un cociente de irracionalidad consustancial al mito que perviviría en los nuevos iconos de la cultura de masas. Véase Dorfles (1973:13-85). Tanto Morin como Dorfles diagnostican en las micromitologias cotidianas un vestigio de religiosidad que, sin embargo, la concepción inequívocamente mistificante del mito planteada por Barthes no llegaría a reconocer.
} 
Apoyándose en el emblemático estudio del fenómeno religioso llevado a cabo por Durkheim en Las formas elementales de la vida religiosa, Maffesoli propone el modelo religioso como metáfora explicativa de las formas de agregación social, de la solidificación de lazos comunitarios, que, a su juicio, sería uno de los rasgos definitorios de las sociedades actuales. Aun cuando la etimología de la palabra religión sea dudosa (re-ligare/re-ligancia), aludiría a aquello que conforma un vínculo colectivo de tipo empático, que configura, en suma, una socialité (socialidad) ${ }^{10}$. Del mismo modo, recalcará Maffesoli, la coparticipación en una simbología común, la consagración en torno a una afinidad simbólica que remite a elementos míticos e imaginarios, re-crea un lazo identitario y consolida la cohesión comunitaria. En la aportación teórica maffesoliana, entonces, lo mítico y lo religioso, en lugar de ser considerados como anacrónicas representaciones del mundo, son revalorizados en cuanto expresiones ideacionales con una destacada eficacia para conformar y mantener la integración simbólica de una colectividad. Así pues, enfatizando, como hace Maffesoli y en general los autores incluidos en esta tradición, el aspecto formal de la religión, en detrimento de sus contenidos doctrinales y de sus concreciones históricas institucionales, del mismo modo que redescubriendo una arquetípica perennidad del mito nacida de un ansia antropológica por transcender lo real, estaríamos en condiciones de desvelar una metamorfosis profana de religión y mito que se estaría expresando en una multiplicidad de fenómenos sociales de nuestra contemporaneidad.

\section{La implicación de lo imaginario en la vida social}

La revalorización de los procesos imaginarios en la vida social, afirma Patrick Tacussel (2002:8), corresponde, en la sociología, al descubrimiento científico del inconsciente para la psicología o la filosofía, permitiendo una reconsideración epistemológica de las creencias, representaciones y sentimientos comunes. En líneas generales, la revitalización sociológica de la noción de imaginario social supondrá una reacción epistemológica frente a una concepción positivista de la ciencia social, heredada de Comte y Durkheim, que ambicionaba el logro de una absoluta explicación objetiva de los hechos sociales, y frente a una metodología empirista en donde el objeto de estudio es contemplado exclusivamente bajo la forma de un dato sensible con una entidad independiente del sujeto que lo experiencia. Como contrapartida, la sociología de lo imaginario incidirá - amparándose en el modelo hermenéutico elaborado por Dürand - en la interpretación de la dimensión simbólica que, encarnada en expresiones culturales tan diversas

\footnotetext{
${ }^{10}$ Noción fundamental para dar cuenta de una sociedad en donde la disolución de los metarrelatos modernos que tensionaban la historia en una ambición de futuro daría paso a una emergente proliferación de comunidades sin un nítido objetivo histórico a alcanzar, pero ligadas por una vivencia intensa del presente y por unos lazos de índole afectivo-pasional.
} 
como los mitos, los ritos, las leyendas o las liturgias contemporáneas, constituye el acervo de significación colectivo. El positivismo y el estructuralismo, de una u otra manera, habían exiliado del conocimiento sociológico a las construcciones culturales mítico-simbólicas. Por su parte, el materialismo marxista había establecido una tajante escisión dicotómica entre el orden infraestructural y el superestructural en donde se imposibilitaba un reconocimiento de la independencia y de la autonomía del universo místico-simbólico. Para la sociología de lo imaginario, sin embargo, el registro de lo simbólico, en el que anida lo imaginario, posee una entidad propia que no se reconoce en una mera ilusión fantasiosa despreciable cognoscitivamente, en suma en una falsa conciencia, en una sublimación derivada de una apriórica carencia de origen material, ni tampoco se encuentra independizado, al modo dualista, de las condiciones histórico-materiales de la vida social ${ }^{11}$. De este modo, nos introduciría en la exploración de un régimen de invisibilidad social no por ello carente de entidad real; lo que demandaría una reformulación del objetivismo subyacente en buena parte de la ciencia social. Así, Ledrut (1987) planteará, frente a una rígida concepción dualista en donde se oponen lo material y lo ideal, lo real y lo imaginario, una ontología social en la que ambos órdenes se hayan entremezclados, en la que el orden de lo imaginario, en una perfecta simbiosis con el orden propiamente material de la vida social, aparece como un ingrediente consustancialmente constitutivo de lo real, dotando a éste de una particular inteligibilidad. De manera que la sociedad real no sería real si no existiera tejida de ciertos esquemas de representación significativa, de imaginarios, que, sin una entidad física, estructuran en cada instante la experiencia social y engendran unas determinadas prácticas sociales. Tal como indica Ledrut, habría imaginarios sociales de la mujer, de la ciudad, de comunidades particulares, de una nación, o imaginarios más amplios como el de la cristiandad o el de la humanidad, que constituyen unas representaciones colectivas diseminadas por el entramado social y difícilmente separables de la llamada sociedad "real". En suma, el reconocimiento de la existencia de lo imaginario, reivindicando el estatuto de lo irreal en la vida social, permitiría captar la profunda imbricación existente entre lo ideacional y lo material sobre la que reposa toda experiencia social.

Morin ha profundizado, durante los años cincuenta y sesenta del pasado siglo, tanto en la investigación del fundamento antropológico de lo imaginario como en la ósmosis existente entre realidad e imaginario en el seno de toda sociedad. Según Morin (2000:115-173), la elaboración de un universo mitológico-mágico,

\footnotetext{
${ }^{11}$ Véase Carretero (2001:251-353). En este trabajo también se enfatiza la duplicidad que acoge el acercamiento a lo imaginario en el pensamiento marxiano. Marx, imbuido por un espíritu racionalista y por la reivindicación de una ontología materialista, comprensible en su contexto histórico, habría desvalorizado la naturaleza de lo imaginario, si bien, al mismo tiempo y en ocasiones de manera contradictoria, le habría reconocido una eficacia social para dinamizar los movimientos contestatarios. Véase, a este respecto, nuevamente Carretero (2001: 13-50).
} 
emanado del despliegue de lo imaginario, debe ser interpretado como un recurso cultural para afrontar la fatalidad de la muerte, puesto que el hombre se abastecería de quimeras y sueños que, con independencia de su condición de verdad o falsedad, le servirían de contraréplica a su marcado destino biológico. De ahí que, a juicio de Morin, la característica más señalada del hombre sea la superposición de lo demens sobre lo racional, la institucionalización de un mundo onírico que se yuxtapone sobre el mundo propiamente objetivo. En comunión con la dimensión racional del hombre, convive, pues, lo irracional; de modo que podría afirmarse que la condición humana se nos revela como intrínsecamente polisémica, como un rostro con múltiples caras. Para Morin, entonces, en todo tipo de sociedades, el mundo imaginario logra constituirse como un ámbito que cohabita con el mundo real y lo vivifica. Así, en concordancia con lo anterior, utiliza como pretexto la ensoñación a la que se abandona el espectador cinematográfico para profundizar en una teoría antropológico-cultural en la que lo imaginario desempeñará un papel nuclear. En una línea similar a la de Dürand, afirma la existencia de una eterna condición antropológica, en la que se enraíza lo imaginario, ligada a una demanda de proyección e identificación consustancial al hombre. Mediante la propuesta de una teoría del doble, Morin (2001:135-193) sostiene que los individuos y las sociedades desdoblan lo real en lo imaginario, transfiguran lo real en un mundo espectral que adquiere una consistencia y entidad propia que, además, acompaña, permanentemente, a la vida de las sociedades. De modo que, finalmente, el mundo real y el mundo imaginario coexisten y se complementan mutuamente. A través de lo imaginario, piensa Morin, la realidad se torna investida de sueño, deviene una suerte de estetización en la que se lleva a cabo un verdadero exorcismo de lo real. Se podría hablar, en efecto, de un campo universal imaginario, en cuanto "estructura antagonista pero al mismo tiempo complementaria de lo real puesto que sin ella no se dotaría de sentido a lo real" (1981:91). Existe, pues, un mundo imaginario, constituido por un depósito de deseos, sueños y fantasías, tanto individuales como colectivas, vetados y sepultados por los imperativos que exigen una acomodación a la realidad. Mundo imaginario, además, que se alza como un mundo alternativo a la realidad socialmente instituida y que reencanta o impregna de magia a la vida cotidiana, compensando, a modo de contrareificación, la constricción cultural del deseo y de la fantasía. Esto aclara el doble movimiento que va de lo real a lo imaginario y de lo imaginario a lo real, el entrejuego constante entre lo real y lo imaginario que anima toda vida social (Ibid:103). A partir de los años setenta, cuando Morin (1998:109-132) desplace su interés hacia una teoría de la complejidad centrada sobre la noción de estructuras auto-eco-organizacionales, lo imaginario se incluirá en la noción de noosfera. La noosfera, universo de significaciones simbólicas que se torna real y con autonomía propia, se enraizaría en el irremplazable cordón umbilical cultural trazado entre el mundo de los hombres y el de los dioses. Habría una ósmosis, una recíproca relación de necesidad entre ambos, puesto que los dioses, que sólo poseerían entidad en función de la demanda 
de los hombres, sacian los deseos y temores humanos, abastecen de sentido a sus vidas.

Para una profunda comprensión de la implicación de lo imaginario en la vida social, es también oportuno resaltar cómo, desde una perspectiva análoga a la de Morin, para autores como Maffesoli (1977:75-95;1998:89-106) o Balandier (1988:242 -284) el despliegue de la modernidad habría provocado, siguiendo la estela frankfurtiana, un desencantamiento de la realidad que, curiosamente, demandaría una efervescencia de lo imaginario. La creciente racionalización y asepsia que coloniza la experiencia social en las sociedades modernas propiciaría una liberación de la fantasía socialmente bloqueada que, de este modo, buscaría hiatos por donde canalizarse y, así, reencantar la cotidianeidad. En efecto, la reificación de la vida social estimularía, como contraréplica, un ansia por remagizar el mundo mediante la reintroducción del ensueño, compensando las carencias simbólicas generadas por una cultura en la que predomina una hipertrofia de lo racional. La modernidad, al consagrar una racionalidad instrumental y productiva en la que se proscribe toda instancia que la extralimite, incitaría precisamente a una segregación de lo imaginario que sería doblegado a los dictados de una razón unidimensional dominante.

\section{Un paradigma para la interpretación de la vida cotidiana}

A partir de los años sesenta del siglo pasado la vida cotidiana pasó a ocupar un lugar preponderante en los análisis sociológicos de raigambre marxista, al ser identificada como el verdadero escenario en donde se plasmaba la alienación social, al ser considerada como el campo privilegiado en el que se podía encontrar reflejado el desposeimiento de las facultades genéricas del ser humano que con anterioridad Marx había localizado en el ámbito de la producción industrial. En esta perspectiva, fundamentalmente crítico-valorativa, la vida cotidiana era contemplada, al mismo tiempo, como un espacio colonizado por una coactiva ideología que, transmitida desde diferentes instancias superestructurales, propiciaba la solidificación de una falsa e incuestionable percepción de la realidad social encaminada al mantenimiento de las contradicciones inherentes al orden social vigente. Los enfoques teóricos de Agnes Heller, Henri Lefebvre y Guy Debord son unos testimonios emblemáticos de esta perspectiva. Asimismo, el pensamiento sociológico de estos autores estaba estrechamente ligado a un consiguiente compromiso con una actitud transformadora de la cotidianeidad, estaba imbricado consustancialmente con el ejercicio de una praxis social.

Como alternativa a esta versión sesgada y unilateral de la vida cotidiana, Michel Maffesoli (1998:31-41), propondrá, a finales de los setenta, un novedoso prisma sociológico que subvierte los análisis teóricos de corte marxista. En este caso, la cotidianeidad no se concibe como un mero espacio pasivo en donde se manifiesta una generalizada alienación e ideología dominante sino, por el contrario, como 
un ámbito en el que se despliega una resistencia subterránea frente a las coacciones impuestas por una racionalizada administración de la vida social, como un contrapoder que, operando en la clandestinidad de lo institucional, constituye un recurso para escapar o transgredir la dominación establecida sobre aquélla ${ }^{12}$. Desde esta óptica, se enfatiza - invirtiendo los análisis tradicionales-, cómo la cotidianeidad estaría mostrando, entonces, un ansia por reapropiarse de una experiencia social previamente doblegada a los imperativos que la colonizan, con el objetivo de dignificar, de este modo, la existencia banal y ordinaria tan denostada en los análisis de raigambre marxista.

La aportación al estudio de la vida cotidiana en autores como Maffesoli, Tacussel o Sansot, se distancia tanto del paradigma crítico-valorativo marxista como del positivista, cristalizándose como una verdadera hermenéutica de lo concreto configurada a partir del legado sociológico de Georges Simmel (con su especial atención a fenómenos minúsculos como la moda o la coquetería), la sociología fenomenológica de Alfred Schütz (con su revalorización de la comprensión como alternativa al modelo epistemológico explicativo-causal), pero en donde la hermenéutica simbólica dürandiana - como ya hemos apuntado con anterioridad - tiene un papel fundamental. Así, en síntesis, el elemento esencial sobre el que pivota el acercamiento a lo cotidiano, en esta tradición sociológica, radicará en una comprensión interpretativa de los componentes míticos, simbólicos, imaginarios, que impregnan los diferentes plexos en los que se entreteje la vida cotidiana, siempre ligada a un reconocimiento de la significación sociológica de aquello supuestamente más insignificante, banal, ordinario. Su distanciamiento fundamental con respecto al positivismo radicará en mostrar que en los minúsculos acontecimientos cotidianos, más allá de su superficie consciente, de su carácter de dato inmediato, se estaría revelando una profundidad mítica subyacente, un noyau coriace - por utilizar la expresión de Dürand (1996:195) - que los dotaría de significación. Desde esta perspectiva, Maffesoli (1981:205-213;1982:146-162; 1985:5-13;1993:79-117;1997) ${ }^{13}$ construirá los pilares de una epistemología de lo cotidiano desde un marco teórico formista y relativista que, además, redescubre el valor de la metáfora como fuente de conocimiento para culminar en una sociología limítrofe con el campo de la estética. Mientras, por su parte, Tacussel $(1984 ; 1995)$ y Sansot $(1986 ; 1996)$ edificarán una sociología figurativa, en donde se desarrollará

\footnotetext{
${ }^{12}$ A este respecto, véase, también, nuestro estudio comparativo de los presupuestos teóricos que subyacen en los análisis de la vida cotidiana de Lefebvre y Maffesoli en Carretero (2002:5-16). Una perspectiva análoga a la de Maffesoli puede encontrase también en De Certeau (1990:11-67).

${ }^{13}$ Una buena muestra de la aplicación empírica de la perspectiva maffesoliana se encuentra reflejada en las investigaciones llevadas a cabo en el CEAQ (Centro de Estudios sobre lo Actual y lo Cotidiano, París V. Sorbona), que este autor funda conjuntamente con Balandier en 1981 y dirige en la actualidad.
} 
una "mostración" poética de lo sensible en la que se saca a la luz el componente imaginario vivificador de la cotidianeidad, que había sido eclipsado tanto por un abstracto conceptualismo como por la obsesiva fijación al dato observable del positivismo.

Por otra parte, en estos autores cobra un especial relieve una reivindicación de la trascendencia sociológica de aquellos aspectos propiamente emocionales, pasionales, sensibles, afectivos, en suma no-racionales, que, inscritos en la naturaleza de la vida cotidiana, habían sido soterrados por una epistemología racionalista en la que el conocimiento es entendido, al modo intelectualista, como una traducción de la singularidad de lo real a un apriórico, objetivo y universal, modelo conceptual que, por definición, se haya distanciado de su objeto de estudio. De esta manera, dicho modelo de conocimiento se encontraría incapacitado para descifrar esa instancia no-racional diseminada en una multiplicidad de órdenes de la existencia cotidiana y que parece rebrotar con fuerza en las sociedades actuales. La captación de este vitalismo social, que anida en la cotidianeidad y que escapa a una constricción a parámetros racionales, pasaría, entonces, por la exigencia de una razón vital, de un raciovitalismo capaz de ensamblar el conocimiento con la plural polisemia caracterizadora de la experiencia social. De ahí que Maffesoli, Tacussel y Sansot se esfuercen en focalizar su mirada hacia lo aparente, hacia un juego de formas que, infravalorado y arrinconado tradicionalmente como frívolo, anodino o trivial, por el discurso sociológico, goza, sin embargo, de una destacada significación en la trama social, permitiendo mostrarnos la ubicación natural en donde se encarna con mayor intensidad ese intrínseco elemento no-racional, propiamente vivencial, que dinamiza la vida colectiva. La coupure epistemológica diseñada a raíz de la modernidad, la que escinde la experimentación de la vida de un monovalente conocimiento racional acerca de ella, sería la que obstaculizaría el reconocimiento de la inteligibilidad, y trascendencia cognoscitiva de aquello que, por frugal, efímero o banal, pasara desapercibido al análisis sociológico.

Al mismo tiempo, para estos autores, el desciframiento de una peculiar lógica cotidiana gobernada en buena medida por lo no-racional, por lo no-lógico, por lo contradictorial, demandaría una renovación del utillaje teórico desde el cual captar las exigencias impuestas por la complejidad de un objeto de estudio que no se agota en una dimensión exclusivamente racional, exigiría una voluntad de estilo que apostaría, siguiendo la estela simmeliana, por un discurso abierto, flexible y fragmentario, frente a la edificación de una construcción teórica rígida, cerrada y sistemática. Además, en esta particular perspectiva paradigmática de acercamiento al esclarecimiento de la naturaleza de la vida cotidiana se conjuga una doble vertiente teórica subyacente:

a) Un compromiso de revalorización de una metodología en la que se revitaliza el estatuto epistemológico de la comprensión como alternativa al modelo explicativo-causal; encaminada a desentrañar el significado de un hecho social que lo es siempre para un sujeto inevitablemente implicado en la experiencia social, 
adoptando, así, las formulaciones de la sociología del conocimiento de Weber y de la sociología de base fenomenológica de Schütz, Berger y Luckmann.

b) La relevancia concedida en el pensamiento sociológico contemporáneo, a partir de los planteamientos de Dürand o Gadamer, a la noción de interpretación, como fundamento para el reconocimiento de una idiosincrasia en las ciencias de la cultura irreductible a los cánones de una reificadora racionalidad científicotécnica.

\section{Lo imaginario y lo político}

La eficacia política de lo imaginario se ha reflejado en las sociedades tradicionales en la capacidad que han poseído las representaciones míticas para legitimar una interpretación significativa de la realidad que justificara un determinado orden y estructura social, solidificándose como matrices globales de sentido que confieren una inquebrantable certidumbre a la forma de asunción de la organización social existente. En sintonía con lo anterior, tal como señala Pierre Ansart (1990:189), el estudio del imaginario político tiene por vocación establecer una continuidad entre la relevancia funcional de lo imaginario en las sociedades tradicionales y el análisis de la lógica del poder en las sociedades modernas, aquellas que se vieron históricamente sometidas a un acusado proceso de laicización. Con independencia, pues, de la dinámica secularizadora que afectaría al cuerpo social, lo mítico, lo sagrado, en cuanto cristalizaciones de lo imaginario, se encontrarían connaturalmente imbricados con lo político, acompañarían a las diferentes manifestaciones históricas del poder. En el específico contexto de la tradición sociológica que nos ocupa $^{14}$, Balandier, Maffesoli y Sironneau han sido los autores que se han ocupado de profundizar con una mayor amplitud en esta temática.

Balandier incidirá en el consustancial aspecto teatrocrático del poder, en las diferentes modulaciones de una dramatización política que, recurriendo a componentes simbólicos e imaginarios, logra consolidar una aquiescencia generalizada en los individuos. El poder, pues, no se ejercería, a su juicio, a través de una desnuda o violenta coerción, como tampoco por medio de una legitimación en nombre de principios racionales, puesto que, de este modo, se encontraría permanentemente amenazada su credibilidad, sino que, más bien, operaría mediante la apelación a una transposición, a una producción y manipulación de símbolos e imágenes bajo una forma de cuadro ceremonial. Así, afirma Balandier (1994b:15-45), en las sociedades tradicionales, en las que predomina un universo simbólico religioso como

\footnotetext{
${ }^{14}$ En este punto, no pueden ser obviadas, no obstante, las perspectivas de Castoriadis (1983; 1989) o de Baczco (1984), que, si bien se desmarcan de la tradición sociológica objeto de nuestro trabajo, han aportado análisis fructíferos de la ligazón existente entre el orden de lo imaginario y el ejercicio de la dominación social.
} 
garantía de justificación del orden social, la legitimación del poder se encontraba respaldada y salvaguardada por un aura de misterio, de sacralidad, de mitología fundacional. Sin embargo, con el advenimiento de la Revolución Francesa, esta sacralidad sobre la que reposaba el poder se perpetuará y mutará bajo un rostro político, configurando una verdadera religión política en la que el culto ritual a los ideales de la República constituirá un excelente medio de regeneración de la fraternidad comunitaria. En las sociedades actuales, nos dice Balandier, se daría un notable giro en la representación de lo político; de modo que la adhesión de los individuos al orden social se alcanzaría por una dramaturgia vinculada ahora a la espectacularización mediática, pero en la que aún se conservaría, no obstante, el componente simbólico-mitológico caracterizador de la naturaleza de lo político en las sociedades precedentes. Por otra parte, las sociedades totalitarias, en las que se promueve una uniformizadora sumisión de los individuos a la entidad estatal, tampoco han sido inmunes a una eficacia política de lo imaginario, puesto que en ellas se exalta y conmemora una mitología que sirve para reafirmar una ficticia unidad social que no da cabida a la disidencia, al mismo tiempo que en ellas se festejan celebraciones que, al modo de una liturgia, sirven como medio de expresión de la dramatización inherente a lo político. En suma, repasando las distintas materializaciones históricas del poder, Balandier recalcará la inevitable ligazón existente entre lo imaginario y lo político.

Maffesoli comparte con Balandier la preocupación por esclarecer la lógica explicativa de la sumisión de los individuos al poder, de la servidumbre voluntaria que La Boétie había formulado como conocida expresión para referirse al inviolable acatamiento del orden social vigente. $\mathrm{Al}$ igual que Balandier, entiende que el orden de lo imaginario desempeña un prioritario papel en los procesos de legitimación de la dominación social, en los mecanismos de aceptación de un statu quo sobre el que descansa toda estructuración social. Según Maffesoli, el elemento fundamental que permitiría dar cuenta de ello es siempre una originaria idée fondatrice de protección que, a través de diferentes modulaciones históricas, sirve de cemento social y posibilita, de este modo, la dominación política. De ahí que lo político remita necesariamente a un principio religioso en su sentido estricto: aquello que re-liga a unos individuos que comparten unos presupuestos comunes, aun cuando esta religiosidad se encarne en instancias tan dispares como El Estado, El Partido, El Progreso, El Servicio, etc.. Por eso, la figura representativa del poder en sus distintas concreciones guardaría un estrecho paralelismo con la del sacerdote, puesto que sería la encargada de procurar, debido a la facultad que se le confiere de comunicación con una idea o mito fundador, una protección simbólica al cuerpo social. Esta imbricación natural existente entre lo político y lo religioso revelaría que una figura política carismática, inspiradora de admiración y a la cual se rinde culto, sea primordialmente una gran conquistadora de almas. A su vez, la adhesión de los individuos al orden social estaría propiciada por una previa necesidad de cumplir una pulsión propiamente re-ligadora que se 
proyecta sobre el representante político, de manera que éste, al estar capacitado para instar a la deidad, logra colmarla y adquirir de ella un provecho. Este esquema teórico, piensa Maffesoli, es el que podría llegar a explicar el magnetismo político que poseen tanto el fascismo como ciertos brotes de populismo emergentes en las sociedades actuales. De ahí que, a juicio de este autor, la tesis más acertada para comprender la naturaleza última de lo político sea invertir la afirmación de Peguy según la cual "todo comienza en mística y todo acaba en política". Además, por otra parte, Maffesoli (1992:27-44; 240-254) insistirá en mostrar cómo el simbolismo juega un importante papel en la dinámica política, puesto que estimula un reconocimiento en imágenes y emblemas que garantizan una integridad y una reafirmación de lo social. Así, las múltiples fiestas y conmemoraciones patrióticas posibilitarían, de una manera más o menos consciente, la consolidación de un fuerte sentimiento de pertenencia al cuerpo social. Tras toda expresión política subyacería, pues, un substrato comunitario, una pasión compartida, que se condensaría en torno a un mito, a un discurso congregador.

Sironneau (1982:201-565), por su parte, analiza la metamorfosis de lo sagrado en la esfera política, a través de lo que se han denominado las "religiones seculares" o "las religiones políticas", centrando su atención prioritaria en torno al nazismo y al comunismo como los dos ejemplos contemporáneos más emblemáticos de dicha metamorfosis. El proceso de secularización que ha afectado a Occidente, con su consiguiente componente laicizador, no implicaría, a su juicio, una desacralización total e irreversible del mundo. Por el contrario, lo sagrado se desplazaría, fundamentalmente, hacia una localización en el terreno de la política, de modo que, desde la segunda mitad del siglo XIX, lo político habría canalizado las aspiraciones, los deseos y los sueños arraigados tradicionalmente en el espacio de lo religioso. De esta manera, las ideologías políticas se habrían transformado en mitologías que abastecen de una estructura global de sentido a la vida social, al mismo tiempo que sus líderes se habrían erigido en personajes carismáticos objeto de culto en razón del rasgo de mediación con lo sagrado que les es atribuido. La tajante escisión entre el ámbito de lo religioso y el de lo político, la conquista de una autonomía de éste respecto de aquél, propugnada a raiz de de la modernidad, habría desembocado en que si bien la política ya no estaría fundada sobre la religión, sin embargo, paradójicamente, la política se convertiría en la religión del Estado, confundiéndose, finalmente, política y religión. En consecuencia, las "religiones seculares", como es el caso del nazismo y el comunismo, manejando el imaginario colectivo, se reapropiarían del componente milenarista característico de las religiones. Por tanto, serían, a juicio de Sironneau, inevitablemente revolucionarias, ya que difundirían en la conciencia de las masas la tradicional esperanza religiosa encaminada a la realización de un mundo nuevo de felicidad y justicia en donde se colmen sus anhelos, una vez que, como resultado de la secularización, esta esperanza ya no está orientada hacia un mundo transcendente. En sintesis, podrían ser interpretadas, pues, como tentativas resacralizadoras derivadas del daño provocado en los órdenes de la legitimación de la significación del mundo y 
de la integración social como consecuencia del proceso de laicización que colonizará Occidente. En ellas, por otra parte, se manifiestan las estructuras míticas, los comportamientos ritualizados, las formas de sociabilidad de tipo comunitario, las expresiones de adhesión y las funciones psico-sociológicas, manifiestas o latentes, caracterizadoras de la idiosincrasia del fenómeno religioso. Así pues, según Sironneau, el proceso de desestructuración de la función simbólica, auspiciado por una secularizada modernidad nucleada en torno a un pensamiento científico-técnico, al que debieran plegarse los diferentes dominios de la experiencia social, ha desencadenado, curiosamente, una reconversión de lo sagrado en el escenario del imaginario político.

\section{El fundamento imaginario de la utopía}

Servier (1982:102-139), en su obra clásica dedicada al esclarecimiento de la noción de utopía a través del estudio comparativo de formulaciones como las de Platón, Tomás Moro y los Socialistas utópicos, la ha considerado como la fijación de una finalidad histórica en la que se vuelcan los anhelos y deseos más profundos del ser humano. Su intención sería compensar las carencias y miserias de la realidad presente. Su orígen es un dinamismo antropológico que, emanado de la imaginación, del sueño, persigue una absoluta transfiguración de lo real. Las elaboraciones utópicas, en sus diferentes expresiones históricas, proponen una felicidad terrestre, un encantado futuro, en el que se condensa el ansia de la imaginación por transcender lo real. En una línea similar a la de Servier, con anterioridad, Mannheim (1997:180-230) ya había sostenido la existencia de una estrecha ligazón entre imaginario y utopía, al afirmar que la mentalidad utópica se nutriría de la aspiración de la imaginación por buscar un refugio en lugares y periodos conforme a sus anhelos, concretándose en un pospuesto ideal de futuro que colmaría esta aspiración. De manera complementaria, Ernst Bloch (1977:81-82) había recalcado que la naturaleza de la utopía descansa en la propuesta de un mundo mejor y más hermoso, como la imagen perfecta, nunca realizada históricamente, en la que se proyectaría un futuro modélico en donde se transcienden la miseria, la crueldad, la dureza y la trivialidad del mundo. Así pues, el fundamento sobre el que reposa la utopía radicaría en una canalización hacia una temporalidad futura del dinamismo que, inherente a la esencia de lo imaginario, ambiciona transgredir las fronteras de la realidad socialmente establecida. Lo imaginario, como fuente de creatividad social, pues, alumbraría potenciales posibilidades de realidad nacidas de la insatisfacción que ésta provoca, vehiculizándose hacia la consecución de un objetivo histórico en donde supuestamente se materializaría la carga eufemizadora que, como hemos visto, Dürand había atribuido a lo imaginario, o lo que Simmel ${ }^{15}$, desde una óptica similar, denominaba como la autotranscendencia de la vida por la imaginación.

${ }^{15}$ El dinamismo creativo que Simmel atribuye al espíritu, la capacidad de éste para generar formas histórico-sociales que sobrepasan y transcienden toda cristalización cultural instituida, guarda 
En consonancia con lo anterior, una de las preocupaciones centrales en la sociología de lo imaginario será la reivindicación de una fecundidad utópica, inscrita en la naturaleza de lo imaginario, vinculada a la construcción de microutopías que emergen espontáneamente en la cotidianeidad, desposeídas, una vez desmoronado el tipo de temporalidad propia de la modernidad, de una proyección de futuro y, por el contrario, fijadas a aspectos concretos de la vida cotidiana. Desde esta óptica, no se trataría, pues, de analizar la galvanización de lo imaginario encaminada, a través de los grandes metarrelatos históricos forjados en las dos últimas décadas, hacia una futurización de la historia, sino, más bien, de reconocer la insubordinación a lo real propia de lo imaginario ligada a una experiencia de lo presente. En este caso, la función desequilibradora de lo imaginario que, según Ledrut (1987:55), implicaba una movilización de la realidad socialmente instituida a través de la ensoñación creadora, el papel herético de lo imaginario del que habla Duvignaud (1990:23-36) ${ }^{16}$, se fijaría ahora a una reinvención de la experiencia socialmente adquirida pero desligada de una dimensión de futuro.

Autores como Maffesoli, Sansot o Alain Pessin han fijado su atención en cómo en diferentes manifestaciones heterogéneas de la vida cotidiana, tales como la música, el deporte o la moda, lo imaginario abastece de ilusión, de inventiva, de irrealidad, a una inerte cotidianeidad, generando, de este modo, una verdadera transfiguración de la experiencia social y un antídoto transgresor de un mundo desencantado. El denominador común que recorre su concepción de la utopía radicaría en la capacidad inherente a lo imaginario para instaurar experiencias sociales alternativas que implicarían una fractura de la vida ordinaria, engendrando una rupturista experimentación de la cotidianeidad. En estos tres autores, entonces, se reivindicarían las microutopías parciales arraigadas en lo más proxémico y deslindadas, por tanto, del ideario político englobante que sirviera para vehiculizar el dinamismo utópico durante los dos últimos siglos. La persecución de una nítida meta histórica da paso, así, a un constante ejercicio de construcción de una vida nueva, a una permanente y al mismo tiempo precaria y frágil reinvención de la experiencia ordinaria. Así, en síntesis, Maffesoli (1993:120-197) ha insistido en el novedoso reencantamiento del mundo resultante de la colonización de lo imaginario en diferentes contextos cotidianos. Por su parte, Sansot (1996:409-420) llevará a cabo una radiografia de la ciudad, destacando los diferentes lugares puntuales en los que se vislumbra el poder de la fantasía como medio de superación de lo real. Y, en lo que atañe a Alain Pessin (2001:177-217), éste diseccionará el significado de una utopía que, en la actualidad, discurrirá por linderos ajenos a lo político.

\footnotetext{
un paralelismo con la función eufemizadora propugnada por Dürand y se encuentra, más o menos implícito, en el trasfondo de la obra de autores como Maffesoli o Sansot. Véase, a este respecto, Simmel (2000:297-313).

${ }^{16}$ Para este autor, especialmente sensibilizado con el nexo existente entre imaginario y creación artística, el papel herético es propio de lo imaginario en cuanto creación de posibilidades de realidad alternativas a la instituida.
} 
RIS

REVISTA INTERNACIONAL DE SOCOLOCIA

No 41, MAYO-AG0ST0, 2005

ÁNGEL ENRIQUE CARRETERO PASÍN

\section{CONCLUSIONES}

Tras esta sintética incursión por las directrices fundamentales en las que se enmarca buena parte de la sociología francesa actual, que convierte al componente imaginario que irriga la vida social en objeto de una atención prioritaria, conviene apuntalar, a modo de recapitulación, las aportaciones sociológicas más originales e innovadoras que ésta suscita.

a) Una relevancia conferida al ámbito ideacional de la vida social que, encarnado en construcciones mítico-simbólicas emanadas del dinamismo inherente a lo imaginario, problematiza los pilares epistemológicos sobre los que se asienta el modelo positivista de ciencia social. Al mismo tiempo, la existencia de un ámbito mítico-simbólico, consustancial a la vida social, revelaría la persistencia y metamorfosis de un cierto componente arcaico que, denostado por una secularizada modernidad, subyace, no obstante, en distintas manifestaciones puntuales de la cultura moderna.

b) El papel esencial atribuido al desciframiento de la lógica de lo cotidiano, de lo ordinario, de lo banal, tradicionalmente desplazado del centro de interés sociológico, en favor del análisis de macroestructuras sociales, recurriendo para ello a una hermenéutica de lo concreto encaminada a revalorizar la oculta significación de aquello aparentemente insignificante y en la que lo no-racional es reintroducido en el objeto de estudio sociológico.

c) Las consecuencias sociológicas derivadas del reconocimiento de la facultad eufemizadora de lo imaginario para transfigurar y reencantar la experiencia social, para instaurar potenciales posibilidades de realidad alternativas a la socialmente instituida. Este reconocimiento posibilita la disponibilidad de un marco interpretativo de la naturaleza de diferentes fenómenos sociales en los que subyace un anhelo por edificar experiencias sociales nacidas de la disconformidad e insatisfacción provocadas por unas petrificadas cristalizaciones culturales, un ansia por vivificar una desencantada existencia social.

d) Repensar la imbricación de poder e imaginario en una doble vertiente: por una parte, recalcando la trascendencia de lo imaginario en las formas de legitimación política y, por otra parte, descubriendo en lo imaginario una fuente de contrapoder, de insubordinación ante una ciega credibilidad en unaúnica posible realidad admitida sin cuestionamiento.

\section{REFERENCIAS BIBLIOGRÁFICAS}

ADORNO, T. y M. HORKHEIMER (1994), Dialéctica de la Ilustración, Madrid, Trotta.

ANSART, P. (1990), Les sociologies contemporaines, París, Éditions du Seuil.

BACHELARD, G. (1997), Poética de la ensoñación, México, FCE. 
BACZCO, B. (1984), Les imaginaires sociaux. Memoires et espoirs collectifs, París, Payot.

BALANDIER, G. (1988), Modernidady poder. El desvio antropológico, Madrid, Júcar Universidad. (1994a), Le dédale. Pour en finir avec le XXe siècle, París, Fayard.

(1994b), El poder en escenas. De la representación del poder al poder de la representación, Barcelona, Paidós.

BARTHES, R. (1999), Mitologias, Madrid, Siglo XXI.

BASTIDE, R. (1970), El prójimo y el extraño. El encuentro entre civilizaciones, Buenos Aires, Amorrortu.

(1972), El sueño, el trance y la locura, Buenos Aires, Amorrortu.

BATAILLE, G. (1987), La parte maldita, Barcelona,'Icaría.

(1993), El estado y el problema del fascismo, Valencia, Pretextos.

BERGSON, H. (1996), Las dos fuentes de la moral y de la religión, Madrid, Tecnos.

BLOCH, E. (1977), El principio de la esperanza, Madrid, Aguilar.

CAILLOIS, R. (1938), Le mythe et l'homme, París, Gallimard.

(1958), Imágenes, Imágenes - Sobre los poderes de la imaginación-, Barcelona, Edhasa.

(1989), Acercamiento a lo imaginario, México, F.C.E.

(1996), El hombre y lo sagrado, México, F.C.E.

CARRETERO, E. (2001), Imaginarios sociales y crítica ideológica, Tesis de Doctorado, Universidad de Santiago de Compostela.

(2002), «La quotidienneté comme objet: Henri Lefebvre et Michel Maffesoli. Deux lectures opposées», Sociétés, $\mathrm{n}^{\circ} 78$.

CASSIRER, E. (1972), La filosofia de las formas simbólicas, vol II, México, F.C.E.

CASTORIADIS, C. (1983-1989), La institución imaginaria de la sociedad, 2 vols. Barcelona, Tusquets.

CORBIN, H. (1993), La imaginación creadora en el sufismo de Ibn'Arabî, Barcelona, Destino.

DE CERTEAU, M. (1990), L'invention du quotidien 1. Arts de faire, París, Gallimard.

DORFLES, G. (1973), Nuevos mitos, nuevos ritos, Barcelona, Lumen.

DÜRAND, G. (1982), Las estructuras antropológicas de lo imaginario, Madrid, Taurus. 
RIS

(1971), La imaginación simbólica, Buenos Aires, Amorrortu.

(1980), L'âme tigrée:les pluriels de Psyché, París, Denoël-Gonthier.

(1983), Mito e sociédade: a mitanalise e a sociología das profundezas, Lisboa, Castalia.

(1984), La foi du cordonnier, París, Denoël-Gonthier.

(1999), Ciencia del hombre y tradición, Barcelona, Paidós.

(1993), De la mitocritica al mitoanálisis: Figuras miticas y aspectos de la obra, Barcelona, Anthropos.

(1996), Le social et le mythique : Pour une topique sociologique en Champs de L'Imaginaire : Mito y sociedad. Método Arquetipológico, Grenoble, ELLUG. Université Stendhal.

(2000), Lo imaginario, Barcelona, Ediciones del Bronce.

DURKHEIM, E. (2000), Sociología y filosofia, Madrid, Miño y Dávila Editores.

(1982), Las formas elementales de la vida religiosa, Madrid, Akal.

DUVIGNAUD, J. (1990), Herejia y subversión, Barcelona, Icaría.

ELIADE, M. (1999), Imágenes y símbolos, Madrid, Taurus.

(2000), El mito del eterno retorno, Madrid, Alianza.

JUNG, C. G. (1991), Arquetipos e inconsciente colectivo, Barcelona, Paidós.

LAPLANTINE, F. (1977), Las voces de la imaginación colectiva: mesianismo, posesión y utopia, Barcelona, Gedisa.

LEDRUT, R. (1984), La forme et le sens dans la société, París, Meridiens.

(1987), "Société réelle et société imaginaire", Cahiers internationaux de sociologie, nº 82.

MANNHEIM, K. (1997), Ideología y utopía, México, FCE.

MAFFESOLI, M. (1977), Lógica de la dominación, Barcelona, Península.

(1998), La conquête du présent. Pour une sociologie de la vie quotidienne, París, Desclée de Brouwer.

(1982), "Conflictos, dinámica colectiva y sociología del conocimiento", Sociología del conocimiento, México, FCE.

(1981), "Pour une sociologie relativiste", Cahiers internationaux de Sociologie, vol LXXI. 
(1993), El conocimiento ordinario. Compendio de sociologia, México, FCE.

(1985), "Pour une sociologie relativiste (II)", Cahiers internationaux de Sociologie, vol LXXVIII.

(1990), El tiempo de las tribus. El declive del individualismo en las sociedades de masas, Barcelona, Icaría.

(1992), La transfiguration du politique. La tribalisation du monde postmoderne, París, Grasset.

(1993), La contemplation du monde, París, Grasset.

(1997), Elogio de la razón sensible, Barcelona, Paidós.

MORIN, E. (2000), El paradigma perdido. Ensayo de bioantropologia, Barcelona, Kairós.

(1964), Las estrellas, Buenos Aires, Editorial Universitaria.

(2001), El cine o el hombre imaginario, Barcelona, Paidós.

(1981), L'Esprit du temps, París, Libre de Poche.

(1998), El Método IV. Las ideas, Madrid, Cátedra

PESSIN, A. (2001), L'imaginaire utopique aujourd'hui, París, PUF.

PRADES, J. A. (1998), Lo sagrado. Del mundo arcaico a la modernidad, Barcelona, Península.

SANSOT, P. (1986), Formes sensibles de la vie sociale, París, PUF.

(1996), Poétique de la ville, París, Armand Colin.

SARTRE, J. P. (1964), Lo imaginario. Psicologia fenomenológica de la imaginación, Buenos Aires, Losada.

SERVIER, J. (1982), La utopia, México, FCE.

SIMMEL, G. (2000), "La trascendencia de la vida y el conflicto de la cultura moderna", Revista Española de Investigaciones Sociológicas, $\mathrm{n}^{\circ}$ 89, pp. 315-330.

SIRONNEAU, J.P. (1982), Sécularisation et religions politiques, París-Nueva York, Mouton Publishers.

TACUSSEL, P. (1984), L'attraction sociale, le dynamisme de l'imaginaire dans la société monocéphale, París, Meridiens.

(1995), Mythologie des formes sociales, París, Meridiens.

(2002), “A sociología interpretativa", Revista Famecos, vol.18, pp. 7-14. 